\title{
PRIMEIRAS NOTAS SOBRE O EFEMERO E O IMPRECISO EM EL HOMBRE QUE TRASLADABA LAS CIUDADES
}

\author{
Cecilla Zokner \\ UFPR
}

\begin{abstract}
RESUMO
A partir de observaçōes de Hans Magnus Enzemberger sobre texto histórico e texto romanesco foram estudados em El hombre que trasladaba las ciudades de Carlos Droguett também outros procedimentos narrativos que irão diferenciar esses romances da conquista da América das obras históriacs sobre as quais ele se baseou.
\end{abstract}

Da conquista da América sabe-se de atos heróicos. Extraordinárias ações que submeteram mil seres, destruiram outros tantos e que foram imortalizadas em monumentos e pinturas e textos cantando loas ao domínio que então foi estabelecido no Continente.

Da multidão que acompanhou os executores da vontade real, pouco se conhece. Do cotidiano, anseios e tristezas desses homens - que a Península Ibérica exaurindo-se relegou - tudo se ignora.

E a História se conta sem as nuances da vida, sem os detalhes do dia a dia. Abstrata. Fria. Impessoal.

Para que os que a fizeram possam viver, para que nos convençam de que viveram é preciso buscá-los na Literatura.

E a História da conquista da América somente se completa com a leitura dos romances Supay el cristiano, Cien gotas de sangre $y$ doscientas de sudor e El hombre que trasladaba las ciudades, a "trilogia da conquista" como os chamou Jacqueline Covo.

No seu trabalho "Historia y elaboración literaria en las "novelas de la conquista" de Carlos Droguett, apresentado por ocasião do Coloquio Internacional sobre la Obra de Carlos Droguett, realizado na França em maio de 1983, a pesquisadora francesa mostrou como, a partir da documentação 
erudita, esquecida, o autor chileno restituiu o "sangue e o suor, os medos e desilusões dos conquistadores"1.

Supay el cristiano e Cien gotas de sangre $y$ doscientas de sudor - na verdade, uma única obra, porém fragmentada em duas por interesse do editor ${ }^{2}$ - narram a fundação de Santiago entre as intempéries e as revoltas dos homens.

El hombre que trasladaba las ciudades trata das mudanças que sofreu a cidade de Barco (as três primeiras realizadas por seu fundador Juan Nuñez de Prado e a última pelo homem que o viera prender, Francisco de Aguirre) antes de ter sido, definitivamente, assentada, em 1553.

Nas três obras, o propósito do autor em relatar "fielmente" o acontecido e uma dependência manifesta das fontes históricas diz, ainda, Jacqueline Covo ${ }^{3}$. Embora $E l$ hombre que trasladaba las ciudades possa parecer essencialmente uma obra ficcional, ao cotejar o texto romanesco com os documentos históricos que tratam dos fatos nele narrados, ficou bem claro para a historiadora francesa que, embora não explicitada a verdade histórica, é nela que se baseia a ficção romanesca.

A cidade de Barco, recém-fundada, antes de se transformar em Santiago del Estero, foi mudada de lugar quatro vezes. A partir dessa pequena epopéia ${ }^{4}$ inserida na epopéia maior que foi a conquista do Continente foram escritos os textos históricos" e o texto ficcional".

Lembrando Hans Magnus Enzemberger, quando em La Literatura en cuanto Historia ${ }^{\top}$ compara textos do historiador Golo Mann com os do romancista Alfred Döblin, percebe-se no texto de Carlos Droguett: "um coletivo que se dissolve em múltiplos sujeitos" e uma narrativa que se faz em muitas vozes. Sobretudo, leitmotiv ${ }^{*}$ que dissolvem a distância, animam o cenário e mesclam à epopéia desse adentrar no Continente, o momento cotidiano.

Sobre esses procedimentos narrativos, principalmente sobre os leitmov, são as linhas que seguem.

1 Covo, J. Historia y elaboraclón llteraria en las "novelas de la conqulsta" de Carlos Dropuett. In: COLOQUIO Internacional sobre la Obra le Carlos Droguett. Polters, Centre de Recherches Latino-Americalnes, 1987. D. 45.

2 Cien gotas de sangra $y$ doscientas do sudor deverla ser o título de uma obra que razós economicas flzeram com que losse dividida em duas, sendo a sezunda parte publicada em 1961 com o titulo orlpinal e a primeira em 1967 cam o tilulo de de Supay el Cristiano.

3 Covo. D. 49.

4 Ver Apéndice I.

5 Por exemplo: LeVillier, R. Nueva crónica de la conquista de Tucumán. Madrid. Rivadeneyra. 1926. BIIVA LEZAFTE. L. El conquistador Francisco do Aguirre. Santjago do Chlle, Fondo Historico y Blbliográffco J. T. Medina. 1953.' VALDTVIA. P. Crónicas del Reino de Chilo. Madrid, Blbltoteca de Autores Espanoles. 1960. v. 131.

6 Ver Apendice II.

7 Artigo publteado em Eco, revista de la cultura de occidonte, 33(201):937-46, jul. 1978.

8 Ver NORIEGA. T. La novelistica de Carlos Droguott: aventura y compromiso. Madrid. Plicros. 1983. p. 82. 
Assim, o sujeito, o individuo que formará o coletivo dos conquistadores será fixado em alguns rápidos traços (barbas demacradas (p.112); jinete rubio y pálido (p.25); manos cuidadas $y$ envejecidas (p.105) $)^{9}$ que geralmente, se aterão menos ao físico do que a um estudo de alma: rostro golpeado $y$ viejo $y$ esos ojos despavoridos, despreciativos o crueles (p.201); era joven y envejecido, tenia el cabello liso y canoso $y$ un rostro magro y cadavérico (p.101); rostro imberbe, cinico, inocente, audaz hasta la desesperación (p.178).

Certamente, poucas vezes houve intenção do retrato. $\mathbf{E}$ a presença dos índios e dos soldados se adivinha sob as expressōes que indicam ação: bater martelos, pregar pregos, serrar madeira, derrubar árvores, acender fogueiras, desembainhar espadas.

Com relação às muitas vozes que em El hombre que trasladaba las ciudades interrompem o contar do narrador básico ${ }^{10}$ - ou um fluir da consciência ou as palavras dirigidas a um interlocutor - elas conferem ao texto um sentido do imediato aproximando o passado do presente, num procedimento narrativo que os motivos irāo completar.

Presentes, também, em outras obras de Carlos Droguett"11 - e o objetivo de especial atenção deste estudo - os leitmotiv aparecem disseminados em $E l$ hombre que trasladaba las ciudades ${ }^{12}$ como elementos cambiantes (o céu, o vento, os sons, os odores, partes da cidade e pertences dos homens) a dinamizar uma ação que a História estratificara.

Num cenário difuso - matas que se diluem na neblina, colinas que se mostram distantes - o céu sob o qual se movem as carretas e os cavalos dos conquistadores é de variados matizes: claro, negro, descolorido, azul, quase escuro, avermelhado. $\mathbf{E}$ de variados aspectos: invernal, tenso, cheio de nuvens finas, alto, imenso. Úm céu que a partir de palavras que $o$ antropomorfizam estabelece um relacionamento com os homens que, a exemplo daquele que os homens já mantêm entre si, pouco tem de consolador ou de cordial: cielo azul y negro, helado y hostil (p.219), cielo tenso y desvaido, un poco amable, un poco cristiano, aunque frio (p.165), cielo negro sin Dios, un cielo implacable (p.160), cielo helado $y$ hostil (p.219).

- Al cltacbes de a hombre quo trasladaba las ciudades re referem adiço Noguer, Barcelons. 1973 .

10 NORIEOA, D. 49.

11 Ver NORIEGA, p. 81 e 82 e ZOKNER, C. Carlos Droruett: o sllenclo amoroso. Cadernoe Hispano-America, Curstlbs, 1:54-68. dez. 1986.

12 Embore tenhs sido publlesdo em 1073. El hombre que trasladaba las ciudades fol escrito na decada de 40. 
Por vezes, também nesse céu, a presença da Lua (helada, nublada, alta y hermosa), das estrelas (salpicadas entre las copas de los árboles), do Sol (tibio, frio, débil).

Outra presença, outro motivo constante, o vento: tibio, frio, helado, caliente, fuerte y tibio, contaminado, cargado de perfume de flores $y$ hierbas (p.133), ele será da espécie dos humanos: solitário y náuseabundo (p.289), lúgubre y revuelto (p.337). Como a chuva (silenciosa, sucia, pérfida). Ou, será arauto de seus destinos quanto é um vento trágico del futuro, quanto é funesto.

No ar, os ruidos do Continente a se misturarem aos rufdos dos recém-chegados. Da natureza são os sons dos bosques, das cascatas, da chuva, dos ventos. São as vozes dos animais: o cantar dos pássaros, o grasnar dos abutres, o zumbir das moscas. com a chegada dos conquistadores, o cacarejar das galinhas, o balar das ovelhas, o mugir dos bois, o ladrar dos cães, o grunhir dos porcos, o relinchar dos cavalos. Vozes humanas, em muitos tons: soluços, sussurros, tosses, queixumes, clamores, lamentos ou cantos, vozes, palavras, gritos, risos, gargalhadas. Ruidos que acompanham os homens no seu labutar: golpes de martelo, ranger das carretas, dos ferrolhos, das portas; ruidos de ferramentas, dos disparos perdidos. Ruídos de crepitar do fogo, do sino da Igreja, do tilintar dos talheres, de passos que passam. $\mathrm{E}$, em meio a esse novo universo de sons El ruido de las espadas $y$ armaduras que se ponian y se sacaban (p.295).

$\mathrm{E}$, assim como os sons se misturam, também os odores da terra, dos vegetais, o cheiro úmido, ácido e doce da madeira recém-cortada, o perfume do trigo, do milho, de folhas frescas e de seiva. Sobre eles, o cheiro da fumaça, de frituras e de comida.

Da cidade, que é feita e desfeita no afã de ser criada ou de ser conduzida para mais longe, vão se esparramando os pedaços pelo caminho percorrido. Reiteradamente aparecem (verdadeiros "leitmotif"), suas janelas, portas, tetos, as forcas e as torres da Igreja. $\mathbf{E}$, esparramados, também, as cadeiras, as mesas, as cujas (camas) e os vasos de flores que deveriam enfeitar sacadas.

Dos homens vão ficando as roupas. Carregadas nas carretas, se perdem. Ou são perdidas no descarregar: calças, botas, camisas, borzeguires, punhos de renda de algum capitão. E objetos (papéis, talheres, cartas de baralho, alguma arma) e objetos litúrgicos (alguma imagem, pedaço de um altar). 
Além desses leitmotiv que, obsessivamente, se repetem em El hombre que trasladaba las ciudades, ainda na busca de efeitos dinamizadores da narrativa dois recursos se farão presentes: o registro do efêmero e o impreciso das informações.

Sensações visuais pontilham a narrativa de momentos fugidios num registro do efêmero que irá lembrar as pinceladas dos pintores impressionistas.

Esses momentos podem se referir às luzes e às cores da natureza (un chorro de sol emerger despedazado desde las sombras (p.295); sólo divisaban destellos cortos y luminosos de sus alas, certeros y suaves relámpagos de color verde o azul o amarillo, un ala sangrienta que aleteaba con urgencia en lo alto, entre las hojas humedas, una cabecita orgullosa $y$ azul que se escurria $y$ deslizaba entre-las ramas (p.282). Ou, originar-se da ação dos homens ao derrubar uma árvore (en el claro silencioso que dejaba el trazo humedo de un árbol enorme que se derrumbaba (p.282) ou ao provocar a queda de um vaso de flores: saltó en al aire un macetero de crisantemos o rosas o pensamientos ( $\mathrm{p} .311$ ).

$\mathrm{E}$, de rara maestria, a imagem do cavalo e cavaleiro que se aproximam dos soldados reunidos perto do fogo; quase tocam as chamas e desaparecem na noite escura.

un caballo paso afuera galopando muy cerca, divisaron sus cascos brillar en la lumbre humeda de la noche, su hocico torcido cubierto de espuma, sus ojos pávidos y jovenes, el jinete alzaba un brazo hacia el cielo, hacia las nubes [...] miraron los cascos del caballo saltar ahi mismo casi pegados a las llamas [...] pero el caballo se habia desvanecido ya entre los árboles (p.375).

Se o efêmero, nos exemplos dados, lembra o desejo do pintor impressionista de fixar o fugidio, a imprecisão das noções de tempo, as dúvidas dos personagens e suas incertezas em muitas informaçōes remetem, também, aos traços difusos com que os mesmos impressionistas representavam a realidade.

Embora em El hombre que trasladaba las ciudades haja obediência a uma cronologia histórica ${ }^{13}$ as referências ao tempo, excetuando estamos en 1550 (p.27) é sempre vaga.

A menção da hora, em geral, segue um verbo cujo tem. po indica probabilidade: debia ser las cuatro de la tarde (p.247); serian las nueve de la noche (p.49). Se, porém, o

13 Ver covo. D. 55 e 56. 
verbo estiver no presente, a imprecisão estará contida em duas possibilidades: son las 5 o 6 de la mañana (p.166). Quando a hora é mencionada com exatidão, na mesma frase estará presente uma noção de tempo antagônica: esperando al anochecer, la madrugada, que falten veinte minutos para las seis de la mañana (p.218).

Não haverá referência a um determinado dia. Sim à tarde, madrugada, noite, manhã. Tampouco muitos meses sāo mencionados. O mês de maio: maio, um dia qualquer, antecedido da imprecisão da hora (exemplo já citado): serían las nueve de la noche de ese día del mes de mayo (p.49). Mas o mês poderá ainda, ser o prazo (depois das chuvas de abril ou de maio) no qual um dos capitães deverá esquecer a traição, o frio, a fome.

As quatro estaçōes aparecem. Como referência ao tem: po da narrativa (era verano ( $\mathrm{p} .32$ ) ou ao tempo que passou (hace dos inviernos) ( $\mathrm{p.269}$ ).

Embora antecedida de uma expressão de dúvida, aparece, ainda, uma data exata, 1570: ano em que Juan Nuñez de Prado acredita já estará a cidade de Barco solidamente construida e seus fundadores então marqueses, duques ou barōes gozando (numa reprodução da sociedade ibérica) de todos os privilégios inerentes e devidos.

Pouco antes, nessa segunda mudança, a notação de tempo se refere ao traçado da cidade que se fará e que estará concluído antes de oito dias.

Essa imprecisão das referências ao tempo ficcional neste romance de Carlos Droguett pode ainda ampliar-se quando a lógica de uma enumeração crescente é interrompida com o uso de uma expressão referencial menor: dentro de algunas semanas, meses, dentro de una pocas noches (p.308). Ou, ain. do, com a deslocação de um sujeito na frase que resultará na antropomorfizaçāo do tempo: o tempo é que verá passar os homens em lugar da tradicional percepção dos homens da passagem do tempo. Dos, tres, quatro dias, talvez siete noches, siete madrugadas los vieros passar (p.142).

Ainda, conferindo imprecisão à narrativa, as dúvidas que assaltam Juan Nuñez de Prado. Aquelas que se referem a acontecimentos cotidianos (quantos meses faz que morreu o padre Germán? Quantas carretas ainda se moviam na escuridão sob a chuva? Quantos prisioneiros, quantos doentes havia na cidade?) e as dúvidas sobre as decisões a serem tomadas: enforcar os dissidentes; matar os enfermos; sacrificar os sonhos dos que desejavam se fixar, possuir um pedaço de terra enfim. 
Dúvidas que podem se expressar, também, em informaçōes ambíguas nas quais se justapōem diferentes elementos relacionados pela conjunção alternativa. São informaçōes que tanto podem se referir à descriçāo de paisagens, como à descrição de pessoas, por exemplo. Uma vez que o informante (narrador básico ou voz do personagem), ou por incapacidade de discernimento, ou por falta de conhecimento, hesita na informação, duas ou mais possibilidades de compreensão se oferecem: horizonte en el que flotaban flecos de nubes heladas, restos de humo de incendios o de neblinas (p.137); unas horribles manos de gitano o aventurero o de bandido (p.204); cabellos enmarañados como humedecidos en agua o lágrimas o sudor (p.112).1t

Trata-se de uma escrita de repetiçōes obsessivas na qual, do grande feito da conquista sobressai a voz dos humilhados e dos vencidos.

Ao servir-se do material recolhido com vistas à elaboração de uma tese universitária (que jamais faria) na criação de um mundo ficcional Carlos Droguett nāo abandonou a trilha dos textos oficiais mas dele fez imergir o cenário do Continente, o trabalho e o sofrimento dos homens.

Debruçou-se sobre os fatos históricos e diluiu-lhe os con. tornos num procedimento narrativo que ao fixar também o efêmero e o impreciso colmou de vida um momento da História da América já esquecido e já cristalizado pelo tempo e o aproximou dos homens de hoje. Não para que eles continuem a cultuar heróis que certamente não existiram. Nem para lastimar as vitimas, essas sim, reais.

Talvez apenas para que não seja esquecido que em nome das consideradas verdades perfeitas, a conquista também semeou a destruição e a morte - árvores, animais, seres humanos - no solo do Continente.

\section{Apêndice I}

El 19 de junio de 1549, Juan Núnez Prado, alcalde de las minas de Potosí, había recibido provisión para dirigir-se a la región de Tucumán y fundar un pueblo en el sitio que le pareciese más conveniente. La decisión, tomada por el licenciado La Gasca, Pacificador del Perú, tenía el doble propósito de buscar expansión territorial y satisfacer al mismo tiempo el deseo de posesión de tierras que tenían muchos soldados descontentes. Desafortunadamente para Nuñez de Prado, su misión habría de incomodar los planes de Valdivia

16 Outros exemplos podem ser observados em expressbes cltadas em outros tóplcos do trabalho: macetero de crisantemos o rosas o pansamientos; certerce y suaves relámpagos de color verde o arul o amarillo, por exemplo. 
en Chile, quien igualmente trataba de ensanchar su território. El conflicto surgió, como era de esperarse, y Barco - nombre de la ciudad originalmente fundada por Núñez - se convertió en una población móvil, montable y desmontable, que Núñez y sus hombres cargaban a cuestas para salvarla de los acechos de Valdivia. Para una idea más completa sobre estos acontecimientos véase Roberto Levillier, Nueva Crónica de La Conquista del Tucumán, tomo I (Madrid: Sucesores de Rivadeneyra, 1927).

In NORIEGA, Teobaldo. La novelística de Carlos Droguett. Madrid, Pliegos, 1983, p.49.

\section{Apêndice II}

Resumo de $E l$ hombre que trasladaba las ciudades de Carlos Droguett.

O primeiro capítulo, "el primer traslado" trata da preparação da mudança, decidida logo após a saída de Francisco de Villagra da cidade. Mais precisamente da dificuldade que a antecede: convencer os soldados de que era necessário mudá-la. O sofrimento de alguns em desfazer o que fora feito e a esperança de outros de vê-la florescer e existir em outro lugar. Nas últimas linhas do capítulo, Juan Nuñez de Prado, a trote, cavalga para alcançar as carretas carregadas com os pedaços da cidade arrancada, deixando para trás outros pedaços e as forcas e os que nela foram enforcados por resistirem à ordem de partir.

No segundo capítulo, "dos, tres, cuatro días" de caminhada, ou sete no mês de junho, uma imensa chuva decidiu o novo assento: no podemos seguir bajo el temporal si no queremos que la ciudad se desintegre y se vaya rio abajo... Nos quedamos... éste es el sitio. E semi-construída estava, ainda a construiam os soldados quando na primavera, em umas poucas carretas, a carregavam de novo. Atrás, ficaram os doentes.

"El tercer traslado" se inicia com um diálogo próximo às árvores e sob a lua algumas noites depois. Escutavam o ruído da água e sentiam que a cidade estaria construída dentro de poucas semanas e que seria para sempre. Este es un hermoso sitio, él más hermoso de todos disseram. Sobre tão claras esperanças, novas esperanças chegam e vão se tornando certezas. Porque Juan Nuñez de Prado, com as carretas prontas e definitivo o desejo de pô-la a salvo dos homens de Pedro de Valdívia tem os olhos postos num lugar que the 
dizem ser Maravilhoso, inmenso y plano, sin sierras ni precipicios.

O último capítulo colocará frente a frente os dois capitães. O que veio para ficar e o que deve partir. Nas carretas, a cidade à espera de seu novo assento para onde, depois de ver partir amarrado a Juan Nuñez de Prado, como das outras vezes, partirá. Será o seu quarto e definitivo "traslado".

ZOKNER, Cecilia. "Para o estudo do adjetivo em El hombre que trasladaba las ciudades". Trabalho apresentado no II Encontro de Professores de Espanhol, realizado em Curitiba nos dias 20 e 21 de maio de 1988 e publicado nas Atas.

\section{REFERENCIAS BIBLIOGRAFICAS}

1 COLOQUIO Internacional sobre la Obra de Carlos Droguett. Poitiers, Centre de Recherches Iatino-Americaines, 1987.

2 DROGUETT, C. El hombre que trasladaba las ciudades. Barcelona, Noguer, 1973.

3 ENZEMBERGER, H.M. La literatura en cuanto história. Eco, revista de cultura de occidente, 33(201):937-46, jul.1978.

4 LEVILLIER, R. Nueva crónica de la conquista de Tucumán. Madrid, Rivadeneyra, 1926.

5 NORIEGA, T. La novelistica de Carlos Droguett; aventura y compromiso. Madrid, Pliegos, 1983.

6 - SILVA LEZAETE, L. El conquistador Francisco de Aguirre. Santiago de Chile, Fondo Historico y Bibliografico J.T.Medina, 1953.

7 Valdivia, P. Crónicas del Reino de Chile. Madrid, Biblioteca de Autores Españoles, 1960. v.131.

8 ZOKNER, C. Carlos Droguett: o silêncio amoroso. Cadernos Hispano-América, Curitiba, 1:54-68, dez.1986. 